\title{
PENGEMBANGAN ALAT PERAGA SISTEM AUDIO UNTUK MENINGKATKAN PEMAHAMAN MAHASISWA PENDIDIKAN TEKNIK OTOMOTIF
}

\author{
Andi Irawan*, Dwi Widjanarko \\ Fakultas Teknik, Universitas Negeri Semarang. Semarang 50229, Indonesia, \\ *E-mail: irawan1594@gmail.com
}

\begin{abstract}
This research aims to know the feasibility and the effectiveness of media equipment installation of car audio system use of props to students in Mechanical engineering Department of Semarang State University. This research is a type of research $R \& D$. The subject of this study is a student with a total of 60 people divided into 2 classes namely the control class and the experimental class. The object of this research is the medium of audio system installation props. The results of the media test percentage assessment amounted to $88 \%$ and the presentation of the material test amounted to $78 \%$, both obtained very decent criteria. The average increase of experimental class learning results was 77.33, while the control class was only 71.47. T test result for post-test value obtained 3.40. The results of the $\mathrm{N}$-gain test calculation obtained an average gain of 0.298 for the control class with a low increase and 0.404 for the experimental class with a moderate increase. The results proved that the installation equipment Media Car audio system is an effective medium to be used as a learning medium.
\end{abstract}

Keywords: props, car audio installation

\begin{abstract}
Abstrak
Penelitian ini bertujuan untuk mengetahui kelayakan dan keefektifan penggunaan media alat peraga instalasi sistem audio pada mahasiswa di jurusan Teknik Mesin Universitas Negeri Semarang. Penelitian ini merupakan jenis penelitian R\&D. Subjek penelitian ini adalah mahasiswa dengan jumlah 60 orang yang dibagi menjadi 2 kelas yaitu kelas kontrol dan kelas eksperimen. Objek penelitian ini adalah alat peraga instalasi sistem audio. Hasil penilaian persentase uji media sebesar $88 \%$ dan persentase hasil uji materi sebesar 78\%, keduanya memperoleh keriteria sangat layak. Peningkatan rata-rata hasil belajar kelas eksperimen yaitu sebesar 77,33, sedangkan pada kelas kontrol sebesar 71,47. Hasil uji t untuk nilai post-test diperoleh 3,40. Hasil perhitungan uji $n$-gain memperoleh ratarata gain sebesar 0,298 untuk kelas kontrol dengan peningkatan rendah dan 0,404 untuk kelas eksperimen dengan peningkatan sedang. Hasil tersebut membuktikan bahwa media alat peraga instalasi sistem audio mobil merupakan media yang efektif untuk digunakan sebagai media pembelajaran.
\end{abstract}

Kata Kunci: alat peraga, intalasi audio mobil.

\section{PENDAHULUAN}

Kegiatan belajar mengajar pada pendidikan dilakukan untuk memajukan pola pikir para peserta didik, agar meningkatkan sumber daya manusia yang lebih modern dengan seiringnya perkembangan jaman. Berjalannya kegiatan belajar mengajar pada pendidikan, sebuah lembaga pendidikan yaitu sekolah merancang sistem batasan waktu dalam menempuh pendidikan yang menekankan pada pemahaman peserta didik.Pendidikan juga sebagai wadah para peserta didik untuk menggali dan meningkatkan potensi yang diarahkan pada tiap bakat 


\section{Andi Irawan \& Dwi Widjanarko}

maupun kompetensi para peserta didik. Sebuah media alat peraga adalah salah satu fasilitas yang harus ada sebagai penunjang pemahaman para peserta didik. Media alat peraga juga sebagai bentuk kegiatan belajar mengajar yang nyata karena terdapat benda kerjanya. Kemudahan pemahaman para peserta didik dalam menangkap suatu ilmu ini dapat memberikan kontribusi besar. Diharapkan merubah kualitas pendidikan lebih baik, karena hasil belajar para peserta didik pastinya akan lebih meningkat dari sebelumnya. Pemanfaatan media pembelajaran secara aktif akan menjadikan para peserta didik memiliki pengalaman belajar yang lebih baik.

Pembelajaran menurut Abdurakhaman dan Rusli (2017:25) pembelajaran adalah suatu proses membangun / memicu, memperkuat, mencerdaskan, dan menstransfer kecerdasan. Menurut Arifin (2012:12) kata dasar "pembelajaran" adalah belajar. Dalam arti pembelajaran dapat diartikan sebagai suatu proses atau cara yang dilakukan agar seseorang dapat melakukan kegiatan belajar. Arifin (2012:13) pembelajaran adalah suatu proses atau kegiatan yang sistematis dan sistematik yang bersifat interaktif dan komunikatif antara pendidik (guru) dengan peserta didik sumber belajar dan lingkungan untuk menciptakan suatu kondisi yang memungkinkan terjadinya tindakan belajar peserta didik baik dikelas maupun diluar kelas, dihadiri guru secara fisik atau tidak untuk menguasai kompetensi yang telah ditentukan. Menurut Gazali (2016:186) menjelaskan pembelajaran bermakna adalah siswa dapat menggunakan pengetahuan yang mereka pelajari untuk memecahkan masalah dan untuk memahami konsep-konsep baru dengan mentransfer pengetahuan mereka untuk situasi dan masalah baru. Menurut Sudrajat (2008:1) menyatakan bahwa media pembelajaran adalah sesuatu yang dapat menyalurkan pesan, dapat merangsang fikiran, perasaan, dan kemauan peserta didik sehingga dapat mendorong terciptanya proses belajar pada diri peserta didik. Menurut Riyana (2012:5-14) media pembelajaran adalah perantara atau pengantar, sedangkan kata pembelajaran diartikan sebagai suatu kondisi yang diciptakan untuk membuat seseorang melakukan suatu kegiatan belajar. Dengan demikian media pembelajaran memberikan penekanan pada posisi media sebagai wahana penyalur pesan atau informasi belajar sehingga mengkondisikan seseorang untuk belajar, dalam kata lain pada saat kegiatan belajar berlangsung bahan belajar (learning material) yang diterima siswa diperoleh melalui media. Menurut Mahnum (2012:28) jadi media adalah perluasan dari guru, pengertian yang dikemukakannya tidak jauh beda dengan pengertian yang dikemukakan oleh Asociation of Education Communication Technology (AECT), yang mana media diartikan dengan segala bentuk dan saluran yang dapat dipergunakan untuk proses penyaluran pesandari kedua pendapat tersebut dapat dipahami bahwa media adalah berkaitan dengan perantara yang 
berfungsi menyalurkan pesan dan informasi dari sumber yang akan diterima oleh si penerima pesan yang terjadi dalam proses pembelajaran.

Menurut Nurseto (2012:22) fungsi media pembelajaran adalah sebagai berikut: 1) Sebagai sarana bantu untuk mewujudkan situasi pembelajaran yang lebih efektif. 2) Sebagai salah satu komponen yang saling berhubungan dengan komponen lainya dalam rangka menciptakan situasi belajar yang diharapkan. 3) Mempercepat proses belajar. 4) Meningkatkan kualitas proses belajar mengajar. 5) Mengkongkritkan yang abstrak sehingga dapat mengurangi terjadinya penyakit verbalisme.

Menurut Sidharta (2005:13) fungsi media pembelajaran adalah sebagai berikut: 1) Memperjelas dan memperkaya/melengkapi informasi yang diberikan secara verbal. 2) Meningkatkan motivasi dan perhatian siswa untuk belajar. 3) Meningkatkan efektivitas dan efesiensi penyampaian informasi. 4) Menambah variasi penyajian materi. 5) Pemilihan media yang tepat akan menimbulkan semangat gairah dan mencegah kebosanan siswa untuk belajar. 6) Kemudahan materi untuk dicerna dan lebih membekas sehingga tidak mudah dilupakan siswa. 7) Memberikan pengalaman yang lebih konkrit bagi hal yang mungkin abstrak. 8) Meningkatkan keingintahuan (curiosity) siswa. 9) Memberikan stimulus dan mendorong repon siswa.

Berdasarkan uraian tersebut tujuan penelitian ini untuk mengetahui tingkat kelayakan media alat peraga yang dikembangkan, dan juga untuk mengetahui tingkat keefektifan hasil belajar peserta didik setelah menggunakan alat peraga instalasi sistem audio mobil

\section{METODE PENELITIAN}

Metode penelitian yang digunakan adalah metode penelitian dan pengembangan (Research and Development/R\&D). Model pengembangan multimedia ini menggunakan model pengembangan ADDIE, dimana model pengembangan ini terdiri dari 5 tahapan yaitu Analyze (analisis), Design (desain), Development (pengembangan), Implementation (implementasi) dan Evaluation (evaluasi). Penelitian ini menggunakan Quasi Experimental Design dengan model Nonequivalent Control Group Design. Dalam desain ini terdapat dua kelompok yang sudah dipilih, kemudian diberi pretest untuk mengetahui kondisi awal kelompok kontrol dan kelompok eksperimen, kemudian diberi posttest untuk mengetahui perbedaan hasil perlakuan yang telah dilakukan antara kelompok kontrol dan kelompok eksperimen (Sugiyono, 2015:116). Desain penelitian Quasi Experimental Design dengan model Nonequivalent Control Group Design dapat ditunjukkan pada tabel 1. 
Tabel 1. Desain Penelitian (Sugiyono, 2015: 116)

\begin{tabular}{llll}
\hline Subjek & Pretest & Perlakuan & Posttest \\
\hline Kelas Kontrol & $\mathrm{O}_{1}$ & $\mathrm{X} 1$ & $\mathrm{O}_{2}$ \\
Kelas Eksperimen & $\mathrm{O}_{3}$ & $\mathrm{X} 2$ & $\mathrm{O}_{4}$ \\
\hline
\end{tabular}

Keterangan:

$\mathrm{X} 1$ : Pembelajaran tanpa menggunakan multimedia differential.

X2 : Pembelajaran dengan menggunakan multimedia differential.

$\mathrm{O}_{1}, \mathrm{O}_{3}$ : Pretest differential.

$\mathrm{O}_{2} \mathrm{O}_{4}$ : Posttest differential.

Setelah nilai hasil pretest dan posttest dari kelas kontrol dan kelas eksperimen didapatkan, diperoleh perbedaan nilai pretest dan posttest yang menjadi acuan dalam menentukan kesimpulan hasil belajar yang diperoleh antara kelas kontrol dan kelas eksperimen.

Subjek penelitian ini adalah 2 kelas dari prodi Pendidikan Teknik Otomotif Jurusan Teknik Mesin Universitas Negeri Semarang. Kelas yang terbagi dua yaitu kelas pretest dan kelas posttest. Jumlah masing-masing kelas yaitu 30 mahasiswa yang mengikuti pelajaran praktik kelistrikan bodi otomotif.

\section{HASIL PENELITIAN}

\section{Kelayakan media alat peraga}

Hasil uji kelayakan dari ahli media terhadap media alat peraga instalasi sistem audio mobil dapat diketahui dari hasil angket penilaian. Adapun hasil analisis data uji kelayakan produk oleh ahli media terhadap media alat peraga instalasi sistem audio, diperoleh jumlah skor total dari penilaian kedua ahli media yaitu 92, dengan presentase $88 \%$. Berdasarkan hasil perhitungan uji kelayakan dari ahli media masuk dalam kriteria sangat layak.

Hasil uji kelayakan dari ahli materi terhadap media alat peraga instalasi sistem audio mobil dapat diketahui dari hasil angket penilaian. Adapun hasil analisis data uji kelayakan produk oleh ahli media terhadap media alat peraga instalasi sistem audio, diperoleh jumlah skor total dari penilaian kedua ahli media yaitu 136, dengan presentase $78 \%$. Berdasarkan hasil perhitungan di atas, uji kelayakan dari ahli materi masuk dalam kriteria sangat layak. 
Perbedaan hasil belajar melalui pretest dan posttest antara kelas kontrol yang tidak mendapat perlakuan dan kelas eksperimen yang mendapat perlakuan yaitu dengan menggunakan media alat peraga instalasi sistem audio dapat dilihat menggunakan analisis data dengan uji-t. Hasil uji-t pretest dan posttest antara kelompok kontrol dan kelompok eksperimen dapat dilihat pada tabel 2.

Tabel 2) Data Nilai Pretest Dan Posttest Kelas Kontrol dan Kelas eksperimen

\begin{tabular}{ccccc}
\hline \multicolumn{2}{c}{ Kelas Kontrol } & \multicolumn{3}{c}{ Kelas Eksperimen } \\
\hline Pretest & Posttest & Pretest & Posttest \\
\hline Ramlah & 1780 & 2144 & 1860 & 2320 \\
Nilai Maksimum & 59,33 & 71,47 & 62,00 & 77,33 \\
Nilai Minimum & 76 & 80 & 76 & 88 \\
& 48 & 60 & 48 & 60 \\
\hline
\end{tabular}

Rata-rata nilai pretest dan posttest kelas kontrol dan kelas eksperimen menunjukkan adanya peningkatan nilai rata-rata tetapi peningkatan yang terjadi pada kelas eksperimen lebih tinggi dibandingkan peningkatan nilai rata-rata yang terjadi pada kelas kontrol. Nilai rata-rata hasil pretest pada kelas kontrol sebesar 59,33 kemudian setelah dilakukan posttest nilai rata-ratanya meningkat menjadi 71,47 terjadi peningkatan sebesar 12,14. Sedangkan pada kelas eksperimen nilai rata-rata hasil pretest sebesar 62,00 kemudian setelah dilakukan pembelajaran menggunakan alat peraga nilai rata-ratanya meningkat menjadi 77,33 terjadi peningkatan sebesar 15,27.

\section{Uji Normalitas}

Hasil uji normalitas data pretest pada kelas kontrol diperoleh nilai chi kuadrat sebesar $\chi 2_{\text {hitung }}=9,039$ pada taraf signifikan $(\alpha=5 \%)$ dengan derajat kebebasan $(\mathrm{dk}=6-1=5)$ diperoleh $\chi 2_{\text {tabel }}=11,07$. Hasil uji normalitas data pretest pada kelas eksperimen diperoleh nilai chi kuadrat sebesar $\chi 2_{\text {hitung }}=1,884$ pada taraf signifikan $(\alpha=5 \%)$ dengan derajat kebebasan $(\mathrm{dk}=6$ 1=5) diperoleh $\chi 2_{\text {tabel }}=11,07$. Berdasarkan hasil tersebut dapat diketahui jika $\chi 2_{\text {hitung }}<\chi 2_{\text {tabel }}$, sehingga dapat disimpulkan bahwa data pretest kelas kontrol dan kelas eksperimen berdistribusi normal.

Hasil uji normalitas data posttest pada kelas kontrol diperoleh nilai chi kuadrat sebesar $\chi 2_{\text {hitung }}=4,286$ pada taraf signifikan $(\alpha=5 \%)$ dengan derajat kebebasan $(\mathrm{dk}=6-1=5)$ diperoleh 
$\chi 2_{\text {tabel }}=11,07$. Hasil uji normalitas data posttest pada kelas eksperimen diperoleh nilai chi kuadrat sebesar $\chi 2_{\text {hitung }}=5,980$ pada derajat kebebasan $(\alpha=5 \%)$ dan $\mathrm{dk}=6-1=5$ diperoleh $\chi 2_{\text {tabel }}$ $=11.07$. Berdasarkan hasil tersebut dapat diketahui jika $\chi 2_{\text {hitung }}<\chi 2_{\text {tabel}}$, sehingga dapat disimpulkan bahwa data posttest kelas kontrol dan kelas eksperimen berdistribusi normal.

\section{Uji Homogenitas}

Hasil uji homogenitas pretest dan posttest antara kelas kontrol dan eksperimen diperoleh harga $F_{\text {hitung }}$ untuk kelas kontrol sebesar 0,485 dan $F_{\text {hitung }}$ untuk kelas eksperimen sebesar 1,440. Dengan dk pembilang $=30-1=29$ dan $\mathrm{dk}$ penyebut $=30-1=29$ pada taraf signifikansi $(\alpha=5 \%)$ diperoleh hasil $F_{\text {tabel }}$ sebesar 1,85. Karena $F_{\text {hitung }}<F_{\text {tabel }}$ maka Ho diterima $(\mathrm{Ho}=$ data homogen $)$ dan dapat disimpulkan bahwa data tersebut homogen.

\section{Uji t}

Tabel 3. Hasil Uji-T Pretest dan Posttest Antara Kelas Kontrol dan Eksperimen

\begin{tabular}{cccc}
\hline & $\mathrm{t}_{\text {hitung }}$ & $\mathrm{t}_{\text {tabel }}$ & Kesimpulan \\
\hline Pretest & 1,78 & 2,002 & Tidak Ada Perbedaan \\
Posttest & 3,40 & 2,002 & Ada Perbedaan \\
\hline
\end{tabular}

Berdasarkan tabel hasil uji-t pretest dan posttest antara kelas kontrol dan eksperimen diperoleh hasil $t_{\text {hitung }}$ untuk pretest sebesar 1,78 dan $t_{\text {hitung }}$ untuk posttest sebesar 3,40. Dengan $\mathrm{dk}=30-1=29$ dan taraf signifikan $(\alpha=5 \%)$ diperoleh nilai $\mathrm{t}_{(0,95)(36)}=2,002$. Nilai $\mathrm{t}_{\text {hitung }}=-1,78$ $<\mathrm{t}_{\text {tabel }}=2,002$ dan $\mathrm{t}_{\text {hitung }}$ berada pada daerah penerimaan Ho, maka data hasil penelitian untuk pretest dapat disimpulkan tidak ada perbedaan hasil belajar yang signifikan, artinya siswa mempunyai kemampuan awal yang sama sebelum dilakukan perlakuan. Sedangkan untuk nilai posttest karena $t_{\text {hitung }}=3,40>t_{\text {tabel }}=2,002$. Kondisi ini menunjukkan nilai $t_{\text {hitung berada }}$ pada daerah penolakan Ho (Ho = tidak ada perbedaan nilai posttest antara kelas kontrol dan eksperimen) maka Ho ditolak, sehingga dapat disimpulkan ada perbedaan hasil belajar yang signifikan setelah dilakukan posttest pada kelas kontrol dan eksperimen.

\section{Uji gain}

Tabel 4. Hasil Uji N-Gain Pretest dan Posttest Kelas Kontrol dan Eksperimen Kelas Pretest Posttest Peningkatan NGain Kesimpulan 


\begin{tabular}{cccccc}
\hline Kontrol & 59,333 & 71,467 & 12,133 & 0,298 & rendah \\
\hline Eksperimen & 62,000 & 77,267 & 15,267 & 0,404 & Sedang \\
\hline
\end{tabular}

Berdasarkan tabel hasil uji n-gain antara kelas kontrol dan eksperimen diperoleh nilai gain untuk kelas kontrol sebesar 0,298 dengan peningkatan hasil belajar sebesar 12,133 sehingga disimpulkan bahwa peningkatan rata-rata hasil belajar pada kelas kontrol masih termasuk dalam kategori rendah $(0,298<0,30)$. Sedangkan nilai $n$-gain untuk kelas eksperimen sebesar 0,404 dengan terjadi peningkaan rata-rata hasil belajar sebesar 15,267 sehingga dapat disimpulkan bahwa peningkatan hasil belajar pada kelas eksperimen termasuk dalam kategori sedang $(0,30<n$-gain $<0,70)$.

\section{HASIL DAN PEMBAHASAN}

Berdasarkan penilaian kelayakan produk oleh ahli media dan ahli materi, alat peraga instalasi sistem audio mobil yang dikembangkan dinyatakan sangat layak. Dapat dibuktikan dari hasil data yang diperoleh pada validasi ahli yaitu ahli media dan ahli materi. Perolehan pada hasil validasi dari ahli media didapatkan persentase kelayakan sebesar $88 \%$. Perolehan pada hasil validasi dari ahli materi didapatkan hasil persentase kelayakan sebesar $78 \%$ sehingga berdasarkan tabel skala persentase penilaian ahli dinyatakan "sangat layak".

Produk akhir media alat peraga instalasi audio mobil yang di uji coba kepada responden para peserta didik Prodi Pendidikan Teknik Otomotif Jurusan Teknik Mesin yang berjumlah 60 orang terdiri dari dua kelas yaitu kelas kontrol dan kelas eksperimen. menunjukkan adanya peningkatan nilai rata-rata tetapi peningkatan yang terjadi pada kelas eksperimen lebih tinggi dibandingkan peningkatan nilai rata-rata yang terjadi pada kelas kontrol. Peningkatan rata-rata hasil belajar kelas eksperimen yaitu sebesar 77,33, sedangkan pada kelas kontrol hanya sebesar 71,47. Hasil uji t untuk nilai post-test diperoleh 3,40. Dengan demikian dapat disimpulkan bahwa media alat peraga yang dikembangkan layak digunakan dan teruji meningkatkan hasil belajar siswa serta mendapat tanggapan sangat baik. Sejalan dengan penelitian yang dilakukan Wicaksono dan Masugino, (2014) pada kelompok eksperimen yang mendapatkan pembelajaran dengan diterapkan panel peraga sistem penerangan mencapai ketuntasan belajar secara klasikal sebesar 81,08\%. Hasil belajar kelompok kontrol yang mendapatkan pembelajaran tanpa panel peraga sistem penerangan mencapai ketuntasan belajar secara klasikal sebesar 48,57\%. Ulasan yang mendukung juga sama dengan yang dilakukan oleh Sugiarta dkk. (2015), dengan hasil presentase ketuntasan hasil belajar siswa 


\section{Andi Irawan \& Dwi Widjanarko}

secara klasikal pada siklus 1 sebesar $40 \%$ dengan nilai rata-rata kelas masing-masing ranah yaitu, 71,25 untuk ranah kognitif, 13,2 untuk ranah afektif dengan kriteria cukup baik dan 18,4 untuk ranah psikomotorik dengan kriteria baik. Pada siklus 2 hasil belajar siswa mengalami peningkatan secara klasikal mencapai 90\% dengan rata-rata kelas untuk masingmasing ranah yaitu 85 untuk ranah kognitif, 14,9 untuk ranah afektif dengan kriteria baik dan 19,45 untuk ranah psikomotorik dengan kriteria baik. Penelitian yang dilakukan Smith,dkk (2011) hasil penelitiannya bahwa menggunakan media instructional ini menunjukkan bahwa pembelajaran multimedia dapat meningkatkan efisiensi dan dapat mempromosikan pengolahan tingkat yang lebih tinggi selama latihan teknik dalam setting yang diawasi. Teori lainnya yang mendukung ialah penelitian yang dilakukan Setiawan dkk. (2009) terdapat perbedaan kemampuan pemahaman mahasiswa sebelum dan setelah menggunkan alat peraga pada mahasiswa D3 otomotif angkatan 2007 Tenik Mesin UNNES yang signifikan. Dapat dilihat dari hasil nilai rata-rata pada tes sebelum menggunakan alat sebesar 52,33 dan nilai rata-rata pada tes setelah menggunakan alat sebesar 69,67, dari data tersebut dapat disimpulkan bahwa mahasiswa mengalami peningkatan sebesar 33,13\% dari hasil sebelum menggunakan alat peraga.

Berdasarkan uraian tersebut dapat disimpulkan bahwa penggunaan media alat peraga instalasi sistem audio mobil teruji efektif sehingga layak digunakan untuk pembelajaran yaitu pada mata praktik kelistrikan bodi otomotif, dibuktikan dengan peningkatan hasil belajar siswa sebelum dan sesudah diberikan perlakuan pembelajaran menggunakan media alat peraga.

\section{SIMPULAN}

Berdasarkan analisis hasil penelitian ini dapat diambil simpulan bahwa, alat peraga instalasi sistem audio mobil yang dikembangkan dinyatakan sangat layak. Dapat dibuktikan dari hasil data yang diperoleh pada validasi ahli yaitu ahli media dan ahli materi. Perolehan pada hasil validasi dari ahli media didapatkan hasil sebesar 92 dari jumlah maksimal yang diharapkan yaitu 104. Dari data tersebut dapat disimpulkan bahwa persentase kelayakan sebesar $88 \%$. Perolehan pada hasil validasi dari ahli materi didapatkan hasil sebesar 103. Dari jumlah maksimal yang diharapkan yaitu 136 Dari data tersebut dapat disimpulkan bahwa persentase kelayakan sebesar 78\%. Penggunaan media alat peraga terhadap hasil belajar peserta didik setelah menggunakan alat peraga instalasi sistem audio mobil terbukti efektif, dinyatakan efektif berdasarkan hasil uji t yang menunjukkan adanya perbedaan hasil belajar yang signifikan setelah dilakukan posttest pada kelas kontrol dan kelas eksperimen. 
Adapun saran yang hendak disampaikan setelah dilakukan penelitian adalah Dengan menggunakan media alat peraga ini telah sesuai dengan yang diharapkan untuk meningkatkan hasil belajar mahasiswa, dengan demikian namun tetap harus memperhatikan keseriusan mahasiswa dan juga fokus agar tercapainya secara maksimal dan merata kepada seluruh mahasiswa. Penggunanaan media alat peraga harus dilakukan secara baik dan benar sesuai dengan manual book, bertujuan agar media alat peraga instalsi sistem audio mobil tidak terjadi kerusakan pada komponen maupun rangkain untuk menjaga kinerja media tetap baik.

\section{DAFTAR PUSTAKA}

Abdurakhman, O., \&Rusli, R. K. 2017. Teori Belajar dan Pembelajaran. Didaktika Tauhid JurnalPendidikan Guru Sekolah Dasar, 2(1).

Arifin, Z. 2012. Evaluasi pembelajaran. Edisi Pertama. Cetakan Kedua. Jakarta Pusat: Subdit Kelembagaan Direktorat Pendidikan Tinggi Islam Derektorat Jendral Pendidikan Islam, Kementerian Agama RI.

Gazali, R. Y. 2016. Pembelajaran Matematika yang Bermakna. Math Didactic: Jurnal Pendidikan Matematika, 2(3), 181-190.

Mahnun, N. 2012. Media Pembelajaran (Kajian terhadap Langkah-langkah Pemilihan Media dan Implementasinya dalam Pembelajaran). ANIDA', 37(1), 27-34.

Nurseto, T. 2011. Membuat media pembelajaran yang menarik. Jurnal Ekonomi\& Pendidikan, 8(1).

Riyana, C. 2012. Media pembelajaran. KEMENAG RI.

Setiawan, E., Wijanarko, D., \& Budoyoni, A. 2009. Pengembangan Panel Peraga Multifungsi Sistem Lampu Kepala Sebagai Upaya Meningkatkan Kompetensi Sistem Penerangan Mahasiswa. Jurnal Pendidikan Teknik Mesin, 9(1).

Sidharta, A. 2005. Media Pembelajaran. Tersedia http://4tkipa.Net modul pembelajaran. 27 Agustus 2018 (10:36).

Smith, A.R., Cavanaugh, C. and Moore, W.A., 2011. Instructional multimedia: An investigation of student and instructor attitudes and student study behavior. BMC medical education, 11(1), p.38.

Sudrajat, A. 2008. Media pembelajaran. http://On Line at httpakhmadsudrajat. wordpress. Com. 27 Agustus 2018 (10:16). 
10 Andi Irawan \& Dwi Widjanarko

Sugiarta, I. N. A., Made Santo Gitakarma, S. T., \& Nugraha, I. N. P. (2015). Penerapan Metode Demonstrasi Berbantuan Alat Peraga Kelistrikan Untuk Meningkatkan Aktivitas dan Hasil Belajar Prakarya dan Kewirausahaan Siswa Kelas X MIA 1 SMA Negeri 2 Singaraja Tahun Ajaran 2014/2015. Jurnal Pendidikan Teknik ElektroUndiksha, 4(1).

Sugiyono. 2012. MetodePenelitian Pendidikan. Cetakan ke-10. Bandung:Alfabeta,cv.

Wicaksono, T. A., \& Masugino, M. 2014. Penerapan Panel Peraga Sistem Penerangan Sepeda Motor SebagaiUpaya Meningkatkan Hasil Belajar Siswa. Jurnal Pendidikan Teknik Mesin, 14(1). 